\section{SISTEM ALARM UNTUK MENDETEKSI KEDATANGAN KERETA API}

\author{
Andre Goslie, Fikri Tri Fadilah, \\ Supriyadi Supriyadi*, Ahmad \\ Nalhadi
}

Teknik Industri, Universitas Serang Raya

\author{
Article history \\ Received : 04-05-2018 \\ Revised : 25-05-2018 \\ Accepted : 28-05-2018 \\ *Corresponding author \\ Supriyadi Supriyadi \\ Email : supriyadimti@gmail.com
}

\begin{abstract}
Abstraksi
Kecelakaan bisa terjadi dimana saja termasuk di perlintasan kereta api yang menjadi tanggungjawab Dinas perhubungan. Perlintasan kereta rata-rata masih menggunakan sistem manual sehingga potensi terjadinya kecelakaan masih tinggi. Perancangan alat ini digunakan untuk meminimalisir kecelakaan yang terjadi dan meningkatkan kewaspadaan masyarakat saat kereta api melintas. Alat ini menggunakan bantuan sensor, sehingga sensor akan mengirimkan sinyal saat kereta api melintas. Pembuatan alat diubah menjadi sistem button karena proses ijin ke pihak kereta api yang panjang. Pembuatan alat bantu ini sesuai masukan ketua RW dan petugas penjaga perlintasan. Alarm dan lampu akan bekerja saat button ditekan dan akan mati sesuai dengan timer yang telah ditentukan.
\end{abstract}

Kata Kunci: Alarm, Kecelakaan, Kereta Api, Sensor

\begin{abstract}
Accidents can occur anywhere including railroad crossings that are the responsibility of the Transportation Department. Train crossing on average still using the manual system so that has high potential for accidents. The design of this tool is used to minimize accidents that occur and increase the awareness of railroad communities pass. The basic design of this tool use the sensor so the sensor will send a signal) when the train passes. The making of the tool is converted into a system button due to the long process of permission to the rail party. The making of this tool is in accordance with the advice of the RW Chairman and the officer of the railroad crossing. Alarms and lights will work when the button is pressed and off according to the predefined timer.
\end{abstract}

Keywords: Alarm, Accident, Railway, Sensor

\section{PENDAHULUAN}

Kereta api merupakan salah satu moda transportasi yang banyak digunakan masyarakat. Kecelakaan pada rel kerata api banyak terjadi pada rel yang melewati jalur-jalur pedesaan. Kecelakaan dapat terjadi akibat tindakan manusia yang tidak mematuhi peraturan (unsafe action) dan kondisi lingkungan yang kurang aman (unsafe condition) (Supriyadi, Nalhadi, dan Rizaal, 2015). Demikian juga dengan perlintasan kereta api yang dikelola dinas perhubungan atau swadaya masyarakat masih rawan kecelakaan karena kondisi perlintasan yang minim dengan alat deteksi atau palang pintu masih bersifat manual tanpa ada alat ambahan lain.

Palang pintu yang berada di Desa Pagar Agung, Kecamatan Walantaka merupakan salah satu palang pintu yang dikelola dinas perhubungan kota Serang. Penutupan palang kereta api yang ada saat ini masih mengandalkan tenaga manusia. Palang pintu ditutup secara manual oleh petugas saat kedatangan kereta api. Penutupan palang hanya dilakukan sebelah sehingga palang pintu yang lain masih terbuka saat kereta api lewat. Kondisi ini menyebabkan banyak terjadi kecelakaan apabila jalan desa ramai atau pada waktu malam hari. Berdasarkan wawancara dengan pihak RW setempat, selama menjabat telah terjadi kecelakaan yang merenggut jiwa sebanyak 6 manusia.

Perlintasan kereta api dijaga satu petugas yang bekerja selama 6 jam. Ada 4 petugas jaga yang secara bergantian menjaga perlintasan kereta api. Pada saat kereta api melintas, petugas akan menutup salah satu palang pintu. Palang pintu yang lain dibiarkan terbuka karena kekurangan petugas dan alat masih manual. Kondisi palang pintu yang masih terbuka memungkinkan terjadinya bahaya kecelakaan terutama saat kereta api melewati perlintasan pada malam hari.

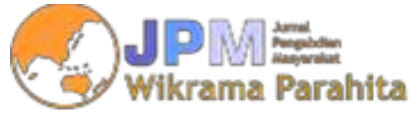




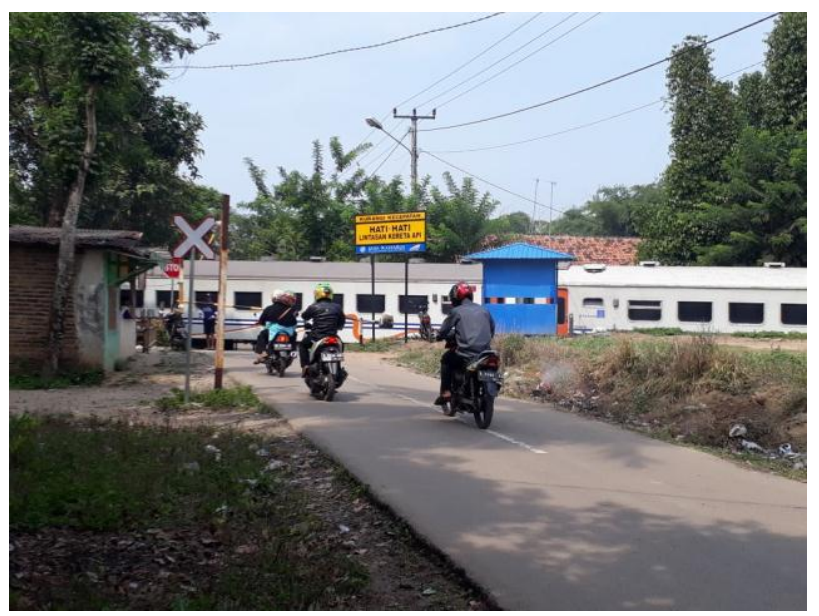

Gambar 1. Kondisi Perlintasan kereta Api

Telah banyak penelitian rancang bangun alat deteksi kedatangan kereta api yang dikembangkan seperti model berbasis mikrokontroller ( Santoso 2013; Yannik et al. 2016; Putra 2017), komunikasi wireless (Kusriyanto dan Wismoyo, 2017), sensor nirkabel (Suharjono, Wardihani, Putri, dan Komariyah, 2017), motion detection (Fayyadh, Sunarya, dan Nugraha, 2015) dan sinyal DTMF (Prayoga, Irawanto, dan Annisa, 2014). Penelitian - penelitian di atas masih berbentuk portotype yang belum teruji langsung di lintasan kereta api karena terkendala beberapa faktor.

Perancangan sistem kedatangan kereta api dibuat untuk meningkatkan kewaspadaan masyarakat ketika ada kereta api lewat. Alat bantu ini dibuat untuk meminimalkan risiko kecelakaan yang terjadi serta membantu penjaga dalam mengatur lalu lintas di area perlintasan kereta api.

\section{TAHAPAN PELAKSANAAN}

Kegiatan ini merupakan proker bersama kelompok 13 dan 14 di Desa Pagar Agung, Kecamatan Walantaka Kota Serang dari tanggal 1 Maret 2018 sampai 30 April 2018. Tahapan pelaksaaan kegiatan ini adalah dengan melakukan observasi di lapangan mengenai kondisi perlintasan kereta api yang ada di desa tersebut. Dari diskusi dengan Bapak RW setempat dan petugas jaga maka disepakati pembuatan alat tambahan untuk meningkatkan keamanan perlintasan kereta api.

Tahapan berikutnya adalah mendiskusikan alat yang dirancang sesuai dengan kebutuhan dan kendala di lapangan. Berdasarkan masukan dari beberapa pihak maka langkah awal adalah membuat sistem alarm dan lampu rotator untuk mendeteksi di lapangan. Pelaksanaan pemasangan alat ini memerlukan waktu sekitar 3 minggu dikarenakan kegiatan KKM hanya dilakukan pada hari Sabtu dan Minggu.

Setelah pembuatan perangkat selesai maka langkah selanjutnya adalah melakukan uji coba kerja alat tersebut, apakah efektif meningkatkan kewaspadaan masyarakat dan memudahkan petugas jaga dalam melakukan tugasnya atau tidak. Uji coba sistem timer bersama dengan petugas jaga sehingga mendapatkan waktu sesuai dengan keinginan petugas. Tahapan selanjutnya melakukan sosialisasi kepada petugas jaga bagaimana cara kerja sistem ini dan bagaimana cara perawatannya atau solusi bila terjadi trouble.

\section{PEMBAHASAN}

Perancangan alat deteksi ini mengimplementasikan prototype yang diajarkan di kampus. Sistem kerja alat ini yaitu, ketika kereta belum melewati sensor lampu led berwarna hijau menyala. Kereta melewati dan menyentuh sensor 1, buzzer akan berbunyi dan dengan delay yang sudah di tentukan motor servo(palang pintu) akan menutup, lampu led berwarna hijau mati dan berubah menjadi merah. Itu menandakan bahwa palang pintu kereta api sudah menutup dan pengendara tidak boleh melawati perlintasan kereta tersebut Ketika kereta api menyentuh sensor 2 motor servo(palang pintu) akan terbuka kembali, lampu led berwarna merah akan mati, dan berubah menjadi warna hijau, begitu seterusnya.

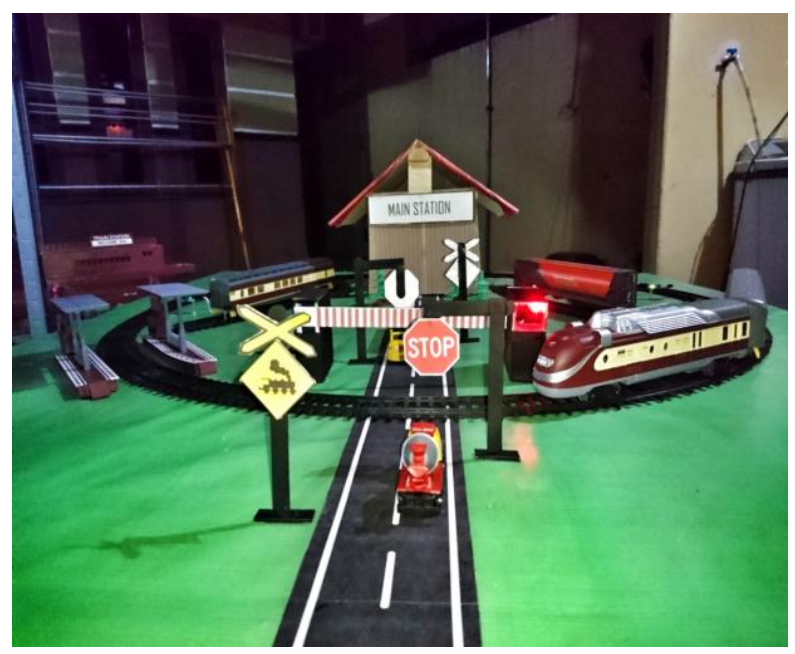

Gambar 2. Prototype Palang Pintu Otomasis

Setelah melalui beberapa diskusi degan ketua RW, penerapan alat ini boleh dilakukan selama membantu sistem penjagaan lintasan kereta api. 
Langkah awal adalah mengukur suhu yang ada di rel kereta api untuk disesuiakan dengan kekuatan sensor yang akan dipasang.

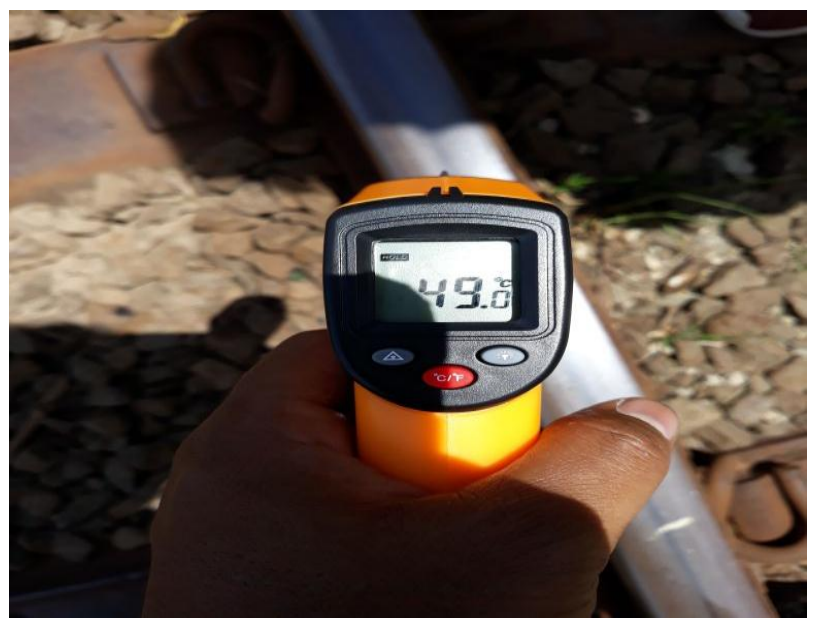

Gambar 3. Pengkuran Suhu Rel kereta

Dari beberpa pengukuran yang dilakukan didapat temperatur suhu $38^{\circ} \mathrm{C}, 41^{\circ} \mathrm{C}$, dan tertinggi $49^{\circ} \mathrm{C}$. Berdasarkan temperature yang diperoleh maka sensor bisa digunakan, karena mempunyai kekuatan sampai temperature $80^{\circ} \mathrm{C}$. Langkah selanjutnya adalah merancang dudukan sensor agar stabil saat kereta melintas.

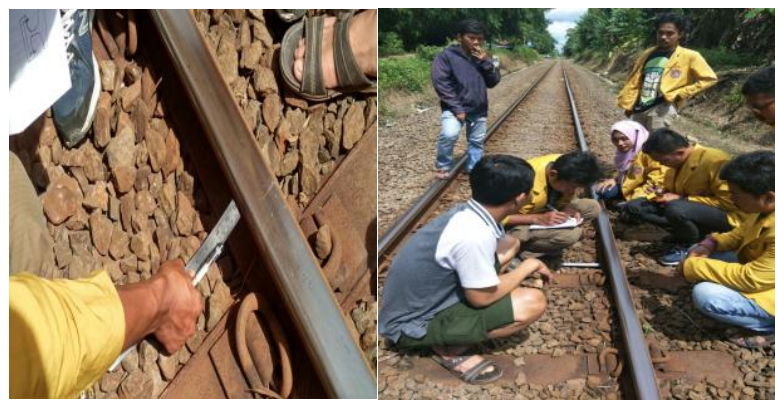

Gambar 3. Perancangan Support Sensor

Support ini berfungsi sebagai dudukan sensor saat pemasangan. Perancangan support dibuat sesuai dengan kondisi di lapangan dan diusahakn agar tidak mengalami getaran yang berlebih saat kereta melintas, karena getaran berlebih yang terjadi akan membuat kinerja sensor tidak optimal. Dari beberapa kali pengujian, diperoleh support dapat menahan atau meredam getaran yang terjadi sehingga support ini layak digunakan.

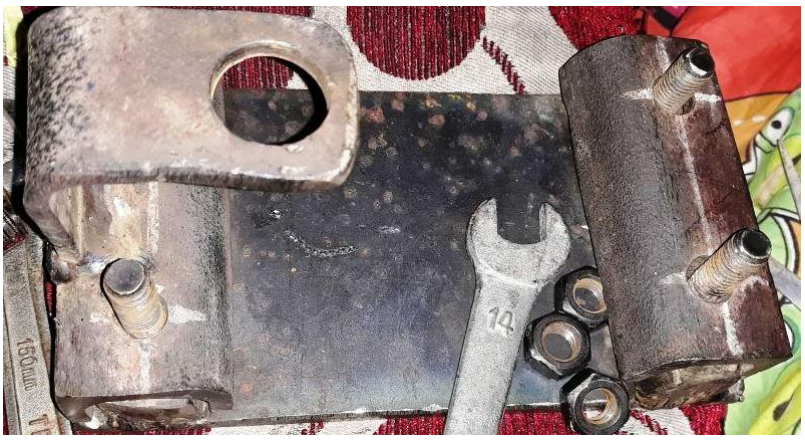

Gambar 4. Support Sensor

Dalam perkembangan di lapangan, pemasangan sensor induction di rel kereta memerlukan persetujuan dari pihak terkait. Melalui arahan petugas kereta api di daerah Walantaka, unuk pemasangan alat tambahan sebaiknya berkonsultasi dengan Stasiun Kereta di Kota Serang. Dari pemamaparan petugas, untuk pemasangan alat tambahan di rel harus mengajukan ijin dulu ke Kantor Kereta Api Pusat di Jakarta. Apabila sudah mendapat persetujuan nanti akan didampingi dari dinas kota dalam pemasangannya. Proses ini memerlukan waktu yang lama karena alat harus di uji dulu di Pusat Penelitian Ilmu Pengetahuan dan Teknologi untuk perlengkapan data sebelum di uji coba di lapangan, sedangkan waktu pelaksanaan KKM hanya selama 40 hari.

Alternatif yang dilakukan adalah sistem deteksi kedatangan kereta api dibuat manual sesuai dengan arahan Bapak RW dan petugas penjaga perlintasan. Sistem deteksi kedatangan kereta dibuat dengan sistem button. Saat kereta api mau melintas petugas tinggal menekan button yang akan membuat sirine dan lampu menyala.

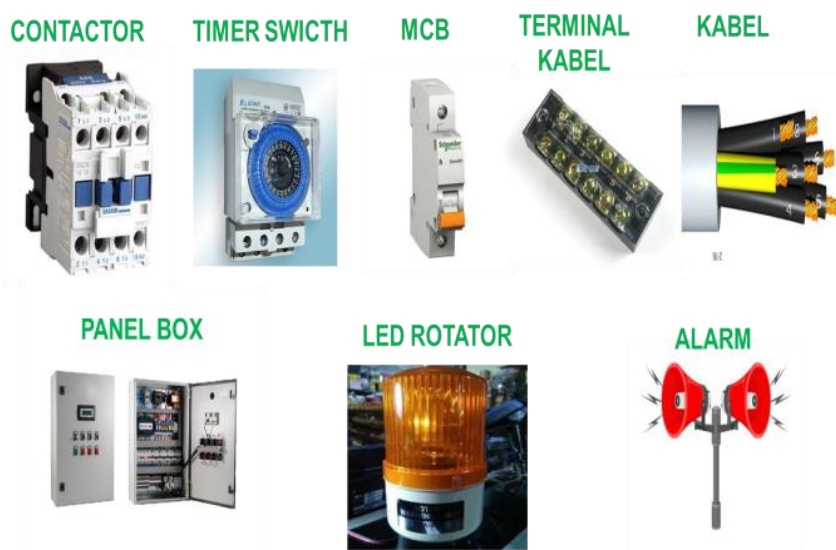

Gambar 5. Peralatan dan Bahan Alat Deteksi 
Secara sederhana sistem kerja alat ini adalah ketika kereta akan melewati perlintasan maka pada jarak sekitar 500 meter alarm dan lampu rotator akan berfungsi sebagai penanda dengan mengunakan push bottom. Petugas penjaga segera menutup palang pintu perlintasan kereta secara manual. Alarm dan lampu led rotator akan berfungsi sebagai tanda bahwa kereta akan melintas. Setelah kereta melewati perlintasan, alarm sudah di atur secara otomatis akan mati dengan sendirinya. Begitu seterusnya setiap kali kereta datang

Langkah awal pembuatan alat ini adalah dengan membuat tiang dan panel box untuk penempatan alarm dan lampu. Tiang dibuat dan dipasang di dua tempat perlintasan agar mudah mudah terlihat sehingga menambah kewaspadaan masyarakat yang mau melewati perlintasan kereta api.Box dipasang di pos penjagaan perlintasan kereta dengan tinggi sesuai dengan keinginan petugas jaga. Setelah panel box sudah terpasang, maka alarm dan lampu dicek bisa bekerja dengan baik atau tidak. Timer untuk kerja alarm disetting sesuai dengan permintaan petugas jaga. Setelah semua berjalan dengan baik dilakukan pemasangan alarm dan lampu di tiang yang telah disiapkan.

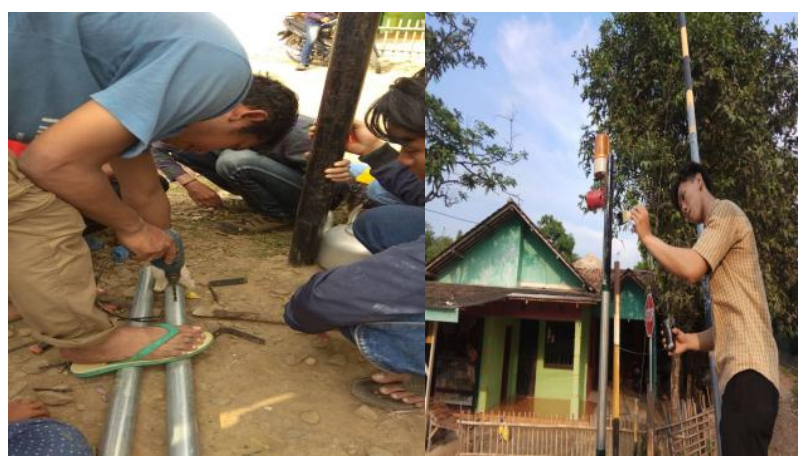

Gambar 6. Pembuatan dan Pemasangan Tiang

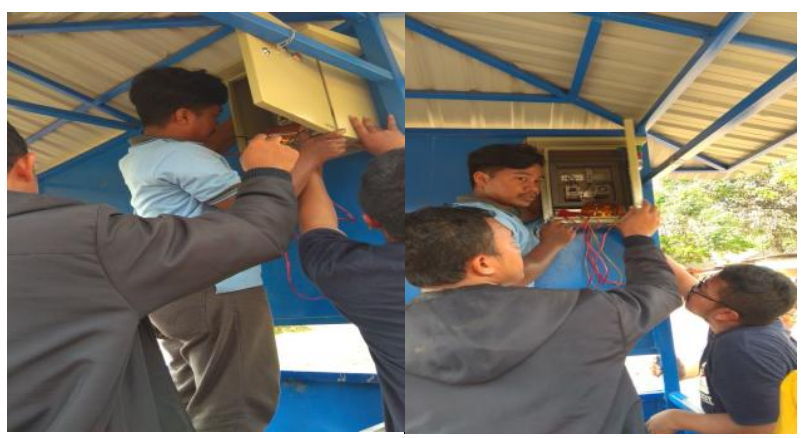

Gambar 7. Pemasangan Panel Box

Berdasarkan beberapa uji coba yang telah dilakukan alat dapat berfungsi dengan baik. Alarm dan lampu dapat bekerja dengan baik saat tombol button ditekan. Timer disetting selama 90 detik sesuai dengan beberapa hasil uji coba dan diskusi dengan petugas. Secara umum alat ini mampu meringankan beban petugas dalam melaksanakan tugasnya dan meningkatkan kewaspaan warga melalui alarm dan lampu rotator. Pemasangan alat ini merupakan tahapan awal dari beberapa tahapan yang direncanakan. Tahapan alat ini adalah memodifikasi palang pintu menjadi otomatis sehingga kedua palang pintu bisa tertutup semua saat kereta api melintas.

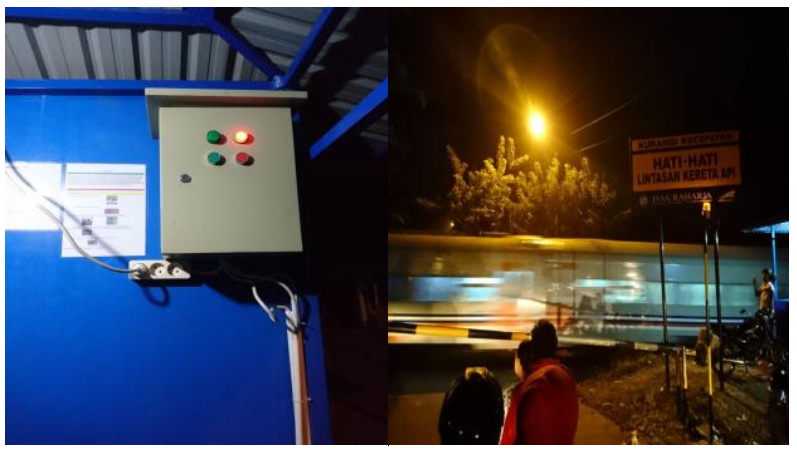

Gambar 8. Kondisi Perlintasan Setelah Pemasangan Alat

\section{KESIMPULAN}

Berdasarkan alat yang telah diaplikasikan, suara alarm dan lampu rotary mampu meningkatkan kewaspadaan warga saat kereta api melintas. Meningkatnya kewaspadaan warga mampu meminimalisir risiko kecelakaan yang terjadi. Alat ini masih jauh dari sempurna. Kegiatan selanjutnya adalah memasang motor pada palang kereta sehingga bisa menutup otomatis. Selain itu akan dilakukan uji coba menggunakan sistem infrared untuk mendeteksi kedatangan kereta api sehingga palang pintu bisa benar-benar otomatis.

\section{UCAPAN TERIMA KASIH}

Ucapan terima kasih yang sebesar-besarnya disampaikan kepada Pihak Desa Pagar Agung, Kecamatan Walantaka yang telah memberikan support dan dukungan atas terselenggaranya kegiatan ini. Terima kasih disampaikan pula kepada Kelompok Kerja Mahasiswa Kelompok 13 dan 14 tahun 2018, Petugas perlintasan kereta api yang telah berusaha merealisasikan kegiatan ini sehingga mampu berjalan dengan baik.

\section{PUSTAKA}

Fayyadh, M., Sunarya, U., dan Nugraha, R. 2015. Perancangan Sistem Otomatisasi Palang Pintu 
Kereta Api Berbasis Motion Detection. eProceedings of Engineering, 2(1), 1-7.

Kusriyanto, M., dan Wismoyo, N. 2017. Sistem Palang Pintu Perlintasan Kereta Api Otomatis dengan Komunikasi Wireless Berbasis Arduino. Jurnal Teknoin, 23(1), 73-80.

Prayoga, Y., Irawanto, W., dan Annisa, S. W. 2014. Sistem Otomasi Kendali Pintu Perlintasan Kereta Api Berbasis Sinyal DTMF (Dual Tone Multi Frequency). Universitas Dian Nuswantoro, Semarang.

Putra, Y. 2017. Prototype Palang Pintu Kereta Api Otomatis Berbasis Mikrokontroler menggunakan Arduino Uno. Politeknik Negeri Padang.

Santoso, A. B. 2013. Pembuatan Otomasi Pengaturan Kereta Api, Pengereman, Dan Palang Pintu Pada Rel Kereta Api Mainan Berbasis Mikrokontroler. Jurnal IImiah Teknik Mesin, 1 (1), 16-23.

Suharjono, A., Wardihani, E. D., Putri, S. A., dan Komariyah, S. 2017. Rancang Bangun Jaringan Sensor Nirkabel pada Prototype Sistem Deteksi Kedatangan Kereta Api Berbasis Sensor Getaran. In Prosiding Sentrinov (Seminar Nasional Terapan Riset Inovatif) (Vol. 3, p. TE134-TE143).

Supriyadi, S., Nalhadi, A., dan Rizaal, A. 2015. Identifikasi Bahaya dan Penilaian Risiko K3 pada Tindakan Perawatan \& Perbaikan Menggunakan Metode HIRARC (Hazard Identification and Risk Assesment Risk Control) pada PT. X. In Prosiding Seminar Nasional Riset Terapan | SENASSET (pp. 281-286).

Yannik, D. I. S. K. A., Sasongko, S., Sugiarto, H. S., dan Wibowo, R. S. 2016. Palang Pintu Otomatis dengan Countdown sebagai Upaya Menghindari Kecelakaan di Perlintasan Kereta. Pelita-Jurnal Penelitian Mahasiswa UNY, 11 (1), 24-34. 